\title{
An Intelligent Voice-Based eMarketplace for Visually Impaired People
}

\author{
Research-in-Progress
}

\section{Fahad Algarni, Yen Cheung, Vincent Lee}

Clayton School of Information Technology, Monash University, Melbourne, Australia.

Email: Algarni.fahad@monash.edu, Yen.Ping.Cheung@monash.edu, Vincent.cs.lee@monash.edu

Received 2013

\begin{abstract}
Today eMarketplaces play a significant role in contemporary life by providing a lot of income and business opportunities to people and organizations throughout the world. Despite innovations in the field of IT, many of eMarketplaces lack the ability to provide appropriate services for people with special needs, especially the blind. Therefore, this paper is focused on incorporating an interface for blind people to participate in the business of eMarketplaces. A proposed model of a voice-based eMarketplace has been introduced using voice recognition technology. Specific blind users of the system are uniquely identified using voice recognition technology to enable them to access the eMarketplace in a secure manner. Further work of this project involves building such as module on an existing eMarketplace.
\end{abstract}

Keywords: eMarketplaces; Voice Recognition; Visually Impaired People; eCommerce; Web Accessibility

\section{Introduction}

Today many areas of life are evolving technologically where people are adopting digital media, which is becoming more efficient and simple to use. Digital technology is considered as one of the major developments in the world of technology due to the fact that it has the ability to be developed and spread progressively [1]. Another major consideration for digital technology is its flexibility and capability in being utilized easily without interfering with the normal way of life. Areas that have so far exhibited a dramatic improvement on technology include but not limited to; engineering, agriculture, transport, gastronomy, communication, finance, trade, media, management and banking. Overall, technology has greatly increased the productivity of the people and comfort has equally increased. However, despite the major innovations in technology, provisions for the physically challenged community such as the blind are limited. For instance, many Internet-based systems such as eMarketplaces remain inaccessible for blind people, raising issue of information asymmetry and social injustice.

According to Leuthold, Baragas and Opwis [2] for blind internet users, an enhanced text user interface is more practical than the graphical user interface, and their results showed a large potential beyond the web content accessibility guidelines for advancing the Internet prac- tice of blind users. They further suggest that empirical studies should be performed to increase insights into navigation strategies and guidelines to build new navigations for the blind. Thus, this paper is dedicated to propose a constructive voice-based eMarketplace that can improve blind internet users experience while browsing the internet.

\subsection{Incorporation of Features to Aid the Visually Impaired People in eMarketplaces}

An eMarketplace is a form of advertising and exchanging of goods and services via the internet. An eMarketplace has greatly provided a chance for buyers and sellers to exchange a wide variety of items without restrictions such as time and location. Hence, eMarketplaces have allowed people to perform different tasks at the same time [3].

A blind person is a person who can not partially or fully use his or her eyes [2]. Due to the problem of using their sense of sight, these people are taught other forms of communication like the Braille language that assists them in the communication. This form of communication can not be easily integrated into the internet. Hence, the need to develop other better ways to integrate them in this technology of eMarketplaces is crucial. This will enhance the internet access and allow the handicapped/blind users to access eMarketplaces more easily 
and conveniently.

From research, it is proven that the blind people have a acute sense of hearing. Accordingly, the introduction of voice technology will be most suitable in this case. Several approaches have been introduced for the integration of the voice technology as one of the facilities on the internet to help blind people access eMarketplaces more easily and conveniently. Those approaches seek to understand blind people, their problems and abilities to access the internet [4].

\section{Literature Review}

\subsection{Forms of Communication Used by Blind People}

Various researchers have suggested more comfortable and easy ways to be used by the handicapped especially the blind to access the internet. There are some specialized equipments that have been developed by scientists that are very sensitive to letter and word recognition, voice and speech recognition. The blind people can communicate in their daily operations with these major forms. Among the most sophisticated systems that have been developed to assist the blind in the area of internet surfing is the Braille surf. Braille is the language of communication used by blind people, which comprises of dots arranged in a specific order to communicate to the blind. It utilizes the sense of touch of blind people as it is proven that besides hearing, they also have the most advanced sense of touch. Despite Braille being one of the main forms of communication, in reality not many people use Braille as it is very difficult to learn [5]. Another system called ALVA Braille has been developed. It utilizes the screen as a display, and it is controlled by the normal operating system of the computers. The output of this system is on a Braille bar or through the use of a voice/speech synthesizer that produces an audible voice which can be received by the blind people [6]. Moreover, another development called Haptic [7] provides a special interface that allows blind users to feel the shapes on the screen. These techniques have been facilitating blind people into the internet browsing so become partially aware of its contents [8].

\subsection{Limitations of the Previous Forms of Communications}

Despite the fact that various innovations have been developed to assist the blind in using the internet and its technology, there are still have some inefficiencies as they do not ultimately assist the blind people in this problem. Most of them have poor and unusable forms of display of graphical features in the internet. As graphical features are very crucial and inevitable in eMarketplaces, they have been enhanced for normal people. However, this has not been done in systems used by the blind to make them feel recognized as part of the human race. Consequently, the entire issue of business and markets will include not just normal people but the blind and other physically challenged people as well [8].

\section{Research Methodology}

\subsection{Research Methodology}

Our aim is to define a basic but an efficient method of achieving usability especially for blind people. Borodin, Bigham and Ramakrishan [4] have mentioned that there is a need for a web browser that assists disabled people to overcome challenges and limitations of accessibility. Due to the fact that blind people who are not yet appropriately considered in the field of internet browsing including eMarketplaces, the main purpose of this paper is to propose an eMarketplace that assist the blind to utilize eMarketplaces. For achieving usability of eMarketplaces we require to have a set of efficient techniques through which can enable handicapped people especially the blind to utilize eMarketplaces easily. Our proposed approach is based on defining voice-based functionalities over the eMarketplaces' interface that can be mapped and connected directly to the entire related databases which involve all required products details. These functionalities are then specified to an eMarketplace specific vocal commands and data sharing can then be achieved through these techniques. Defining these voice-based functionalities to the eMarketplaces' interface is possible through an intelligent voice-based assistant The voicebased assistant is a function of an eMarketplace in which enables database text reader, which provide a voice responds, allowing data to be retrieved across eMarketplace' applications. The information then can be achieved in a well-defined vocal manner enabling handicapped and blind people to interact with the entire online market activities. The voice-based eMarketplace module promises to expose the information content of the eMarketplaces resources which apart from text also includes images' condition description. The proposed structural design is defined and explained with all required supportive figures and how the voice-based eMarketplace module and its techniques are used in making this structural design is discussed in the following subsections.

\subsection{Defining the Methodology}

In our architecture, we assume the availability of a standard eMarketplace database, which consists of all products' prices and details. For the entire database in the architecture, voice-based assistance declarations are defined to the eMarketplace system. These declarations 
consist of all variables that will be used in data mining and they expose the eMarketplace contents in its database to the eMarketplace interface. Internal matching is defined between the eMarketplace database and its related interface. The aim is to achieve usability of eMarketplace by ensuring that handicapped people especially blinds utilize eMarketplaces with confidence by referring to the voice-based assistant. Voice-based assistant takes the vocal entry from the handicapped user to perform the matching procedure on the desired eMarketplace. The vocal entries that the handicapped user speaks after hearing the vocal instructions which provided by the voice-based online assistant referring to the internal matching of eMarketplaces components and the result is given back. In case of that the vocal entry was matched or found, the voice-based assistant will further proceed the order for the handicapped/blind user. Otherwise, if the vocal entry is not matched or found, the voice-based online assistant will divert customer automatically to a customer care representative (CCR) using voice over IP call through the eMarketplace system. In such a case, the handicapped/blind customer will have the full opportunity to speak and explain his/her desired product with the CCR. The architecture is shown in Figure 1. It shows the overall plan of eMarketplace voice-based system including the relevant database, the voice-based online assistant which located on the interface, the CCR and how the blind users interact with it.

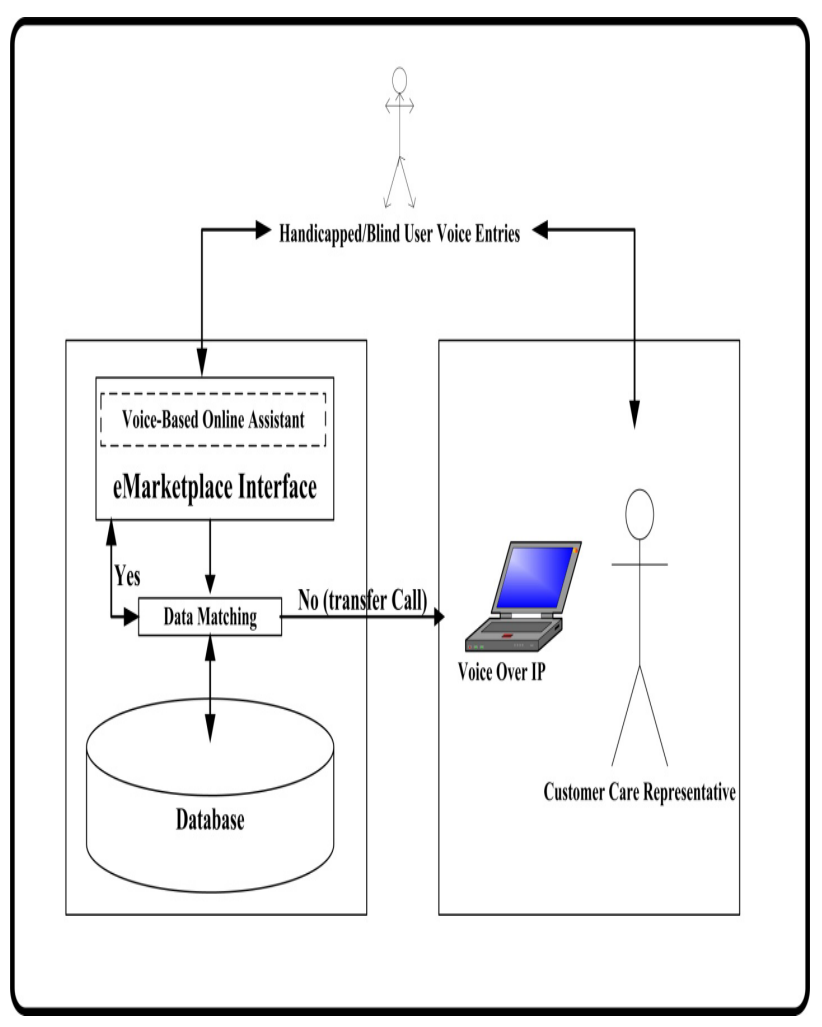

Figure 1. Architecture of the Voice-based eMarketplace.

\subsection{Role of the Proposed Voice-Based eMarketplace Interface}

The voice-based eMarketplace is an efficient technique of demonstrating information of traditional eMarketplaces. It represents information in a voice manner that can easily be understood by handicapped people especially blinds. It provides an opportunity for them to fully participate and complete their online shopping without current difficulties. In addition to the benefits of the eMarketplaces technology for both buyer and seller such as, connectivity and flexibility [3], handicapped people will have the ability to contribute positively to the field. Considering this segment of society is not only a humanitarian act, but is a quantum leap in the history of eMarketplaces. Thus, implementing such a technique is crucial to keep pace with the continuing evolution eMarketplaces.

\subsection{Methodology Architecture Specifications}

To demonstrate the architecture, we will consider an example of an eMarketplaces that sells school products. Essentially this school eMarketplace will one or more than one product categories or types stored on its related database. The database normally stores the information of its products availability and descriptions. Suppose a blind person wants to check the availability of a leather bag. Then, he/she may wish to know the price and buy the desired product. The voice entry 'leather bag' will be received via the voice-based online assistant that built in the school eMarketplace interface. Then, the voice-based online assistant will transfer the vocal entry for matching its availability. In case if the desired product is found, the voice-based online assistant will read out the results back to the handicapped/blind customer and will follow the purchasing procedure vocally. Otherwise, if the vocal entry is not found, the voice-based online assistant will directly divert the call to a customer care representative who will be able to further assist handicapped/blind customer to complete their online shopping transaction. Further explanations of our proposed voice-based eMarketplace and its relevant actions that can be performed by the blind person is illustrated in the event table " see Table 1 ” and the related use case, activity diagrams.

\subsection{Event Table Analysis}

As handicapped/blind person could perform the normal purchasing eMarketplaces' activities that includes searching, choosing and buying. “Table 1" represents sequence of functions for the voice-based eMarketplace system on an event-by-event basis in a summary form. It involves the use cases of each event that will then assist in depicting the Use Case diagram that will comprise the practical requirements of the system. 


\subsection{Use Case Diagram Clarifications}

The use case model "See Figure 2" describes the identified events showed in Table 1, and links them to all actors (Blind Customer, Voice-Based Online Assistant and eMarketplace system); therefore, it represents the participation between all elements.

In order to clarify the functionality of the system we also produce a relevant activity diagram. Activity diagram represents in depth the specific internal activities of the system. It can be used to support any level of use cases that presented in the use case diagram. In our proposed system we use it to simplify the scenario of the interaction between the blind user and the voice-based eMarketplace interface including how the system will divert blind customer call using VoIP technique "see Figure 3".

Table 1. Sequence of events for voice-based eMarketplace.

\begin{tabular}{|c|c|c|c|c|c|}
\hline Event & Trigger & Source & Use Case & Response & Destination \\
\hline $\begin{array}{l}\text { 1. Customer Checks } \\
\text { Item Availability }\end{array}$ & Item Enquiry & Customer & $\begin{array}{l}\text { Check Item } \\
\text { Availability }\end{array}$ & $\begin{array}{c}\text { Item Availability } \\
\text { Details/ Or } \\
\text { Transfer customer’s } \\
\text { call (VoIP) }\end{array}$ & Customer \\
\hline $\begin{array}{l}\text { 1.1. CCR Checks } \\
\text { Item Availability }\end{array}$ & Item Enquiry & CCR & $\begin{array}{l}\text { Check Item } \\
\text { Availability }\end{array}$ & $\begin{array}{l}\text { Item Availability } \\
\text { Details }\end{array}$ & CCR \\
\hline $\begin{array}{l}\text { 2. Customer or CCR } \\
\text { Places an Order }\end{array}$ & New Order & Customer or CCR & Create New Order & $\begin{array}{c}\text { Order Confirmation/ } \\
\text { Order and Customer } \\
\text { Details }\end{array}$ & $\begin{array}{l}\text { Customer or CCR/ } \\
\text { eMarketplace System }\end{array}$ \\
\hline $\begin{array}{l}\text { 3. Payment validates } \\
\text { transaction }\end{array}$ & $\begin{array}{l}\text { Transaction } \\
\text { validation }\end{array}$ & $\begin{array}{l}\text { eMarketplace } \\
\text { System }\end{array}$ & Payment validation & $\begin{array}{l}\text { Payment approval } \\
\text { Shipment order }\end{array}$ & $\begin{array}{l}\text { Customer/ } \\
\text { Shipment }\end{array}$ \\
\hline
\end{tabular}

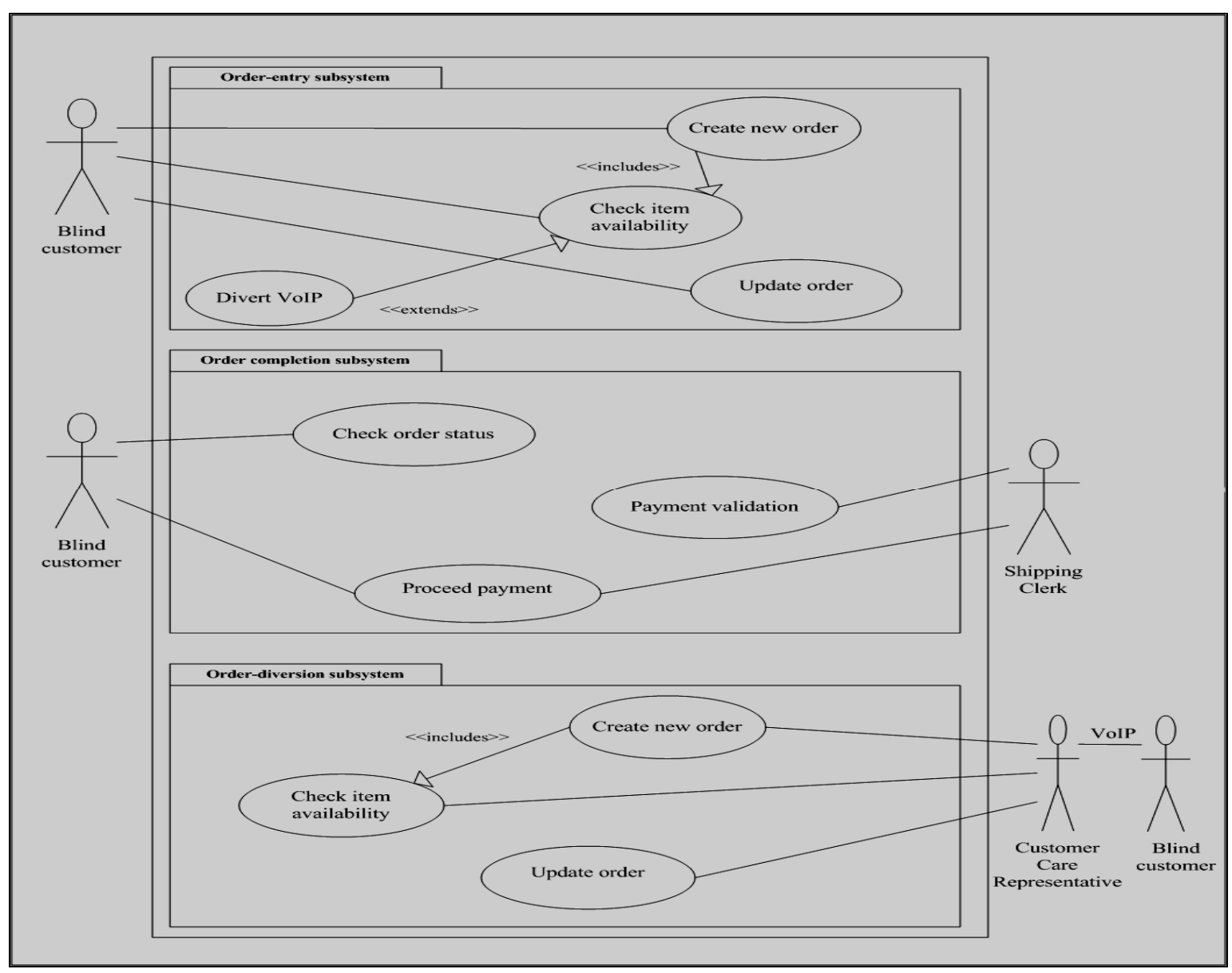

Figure 2. Use case diagram. 


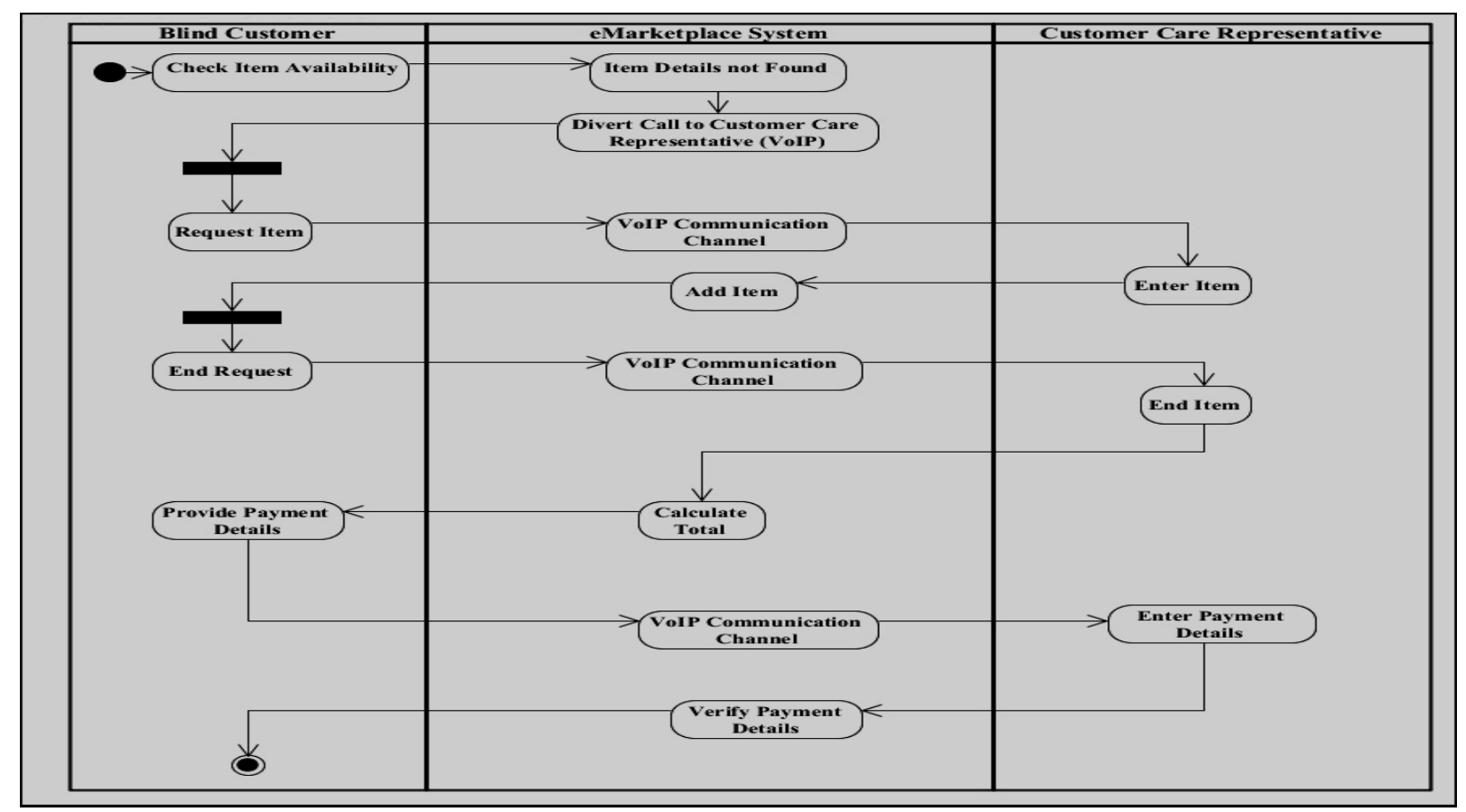

Figure 3. Use case diagram.

As a quick glimpse at "Figure 3", it demonstrates the scenario of checking item availability use case which is included with the create new order use case. For example, when a handicapped/blind eMarketplaces user places a vocal order to purchase an item, the order then will be received by the voice-based eMarketplace system for processing. After data matching there will be tow cases: the first case is that when the item is found then the voice-based eMarketplace system will persist the order with the handicapped/blind user in a vocal manner. The second case is that when the item is not found, the system here will not reject the order, instead it will directly convert the handicapped/blind users to a customer care representative to further facilitate the completion of the purchasing process.

\section{Conclusion and Future Work}

\subsection{Future Wrok}

Further studies can be conducted to implement the proposed voice-based eMarketplace. For instance, the proposed system can be developed as a Blind Interface Module, which can be used as an add-on facility to an existing eMarketplace. This module can be activated when needed.

\subsection{Conclusion}

In conclusion, the assimilation of technology into the field of eMarketplaces has an important role particularly in addressing the needs of everybody including those who are physically challenged. Thus, further developments and enhancement of Internet applications should include investigations of 'comfortable' forms of eMarketplaces that are suitable for the handicapped, especially the blind. As mentioned earlier, there has been commendable attempts to generate more comfortable ways for the blind to be part of the changing technology especially eMarketplaces. This has included the use of text readers, voice recognition devices and speech synthesizers. Although there are challenges in their applications, they can be of great assistance to the blind and even with some modest improvements they can lead to major breakthroughs in introducing the blind to eMarketplaces technology. This will in turn expand business of eMarketplaces. In this paper, we have proposed a voice-based module for eMarketplaces for handicapped/blind people. The system can deal with blind people using voice input and output commands. The event table of the scenario for the purchasing process has been described to illustrate the proposed system. Overall, the system can be crucial for both the blinds and people with typing or browsing difficulties.

\section{REFERENCES}

[1] W. Veen, "How technologies change our schools, companies and governments," in Proceedings of the International Workshop on Enterprises 38; Organizational Modelling and Simulation (EOMAS '09). ACM, New York, NY, USA., 2009.pp. 1-5.

[2] S. Leuthold, J. A. Bargas-Avila, and K. Opwis, "Beyond 
web content accessibility guidelines: Design of enhanced text user interfaces for blind internet users," International Journal of Human-Computer Studies, vol. 66, pp. 257-270, 2008.

[3] T. Wei, J. Kan, and Z. Zi-gang, "Supply Chain Coordination Study Based on Retailers' Inventory Transshipment via eMarketplace," in International Conference on Management Science and Engineering, ICMSE. , 2007, pp. 1019-1024.

[4] Y. Borodin, J. P. Bigham, A. Stent, and I. Ramakrishnan, "Towards one world web with HearSay3," in Proceedings of the international cross-disciplinary conference on Web accessibility W4A, NY, USA, 2008, pp. 130-131.

[5] H. Burton and D. G. McLaren, "Visual cortex activation in late-onset, Braille naive blind individuals: an fMRI study during semantic and phonological tasks with heard words," Neuroscience letters, vol. 392, pp. 38-42, 2006.

[6] J. J. Lazzaro, "Helping the Web help the disabled," Spectrum, IEEE, vol. 36, pp. 54-59, 1999.

[7] C. Sjostrom, "Designing haptic computer interfaces for blind people," in Signal Processing and its Applications, Sixth International, Symposium on., Kuala Lumpur, 2001, pp. 68-71 vol. 1.

[8] M. King, J. W. Thatcher, P. M. Bronstad, and R. Easton, "Managing usability for people with disabilities in a large web presence," IBM Systems Journal, vol. 44, pp. 519-535, 2005. 